\title{
Forms of Politeness Within the Speech Act of Apologies Compared to the Parameter Gender in the English Language
}

\author{
Milena Mrdak Micovic, M.A. \\ Department for the English Language and Literature, Faculty of Philosophy \\ University of Montenegro \\ Email:milenche@t-com.me
}

Doi:10.5901/mjss.2014.v5n13p199

\begin{abstract}
The question of politeness in language has been one of the most popular in linguistic studies since the second half of the twentieth century, and as such, has intrigued us to make a presentation of forms of politeness in the speech act of apologies within the English language system. Interesting and complex at the same time, primarily due to the interweaving of grammar, psychology and sociolinguistics, this problem proved to be a huge challenge, asking for both theoretical and discussions of the results obtained in practice. This paper presents the results of a case study conducted on the corpus obtained from a popular reality show in order to show whether the women, and to what extent, tend to use more tentative language forms within the speech act of apologies.
\end{abstract}

Keywords: politeness, language and gender, speech act of apologies, modality, hedging.

\section{Introduction}

As a type of speech act, the apology has been the object of numerous studies that attempted to clarify what exactly an apology is, how the different ways of apologizing can be classified, and also how this particular speech act is performed.

Recent linguistic researches have shown that communication is not only the way in which a piece of information is transmitted from the speaker to an addressee, but also "an equally important mean of establishing, maintaining, and even terminating social relationships with other people." (Sifianou, 2000, p.12) While spoken communication, according to Robin Tomah-Layoff (1975), has been characterized as spontaneous, it is often seen as unclear and confusing with numerous ambiguous forms and reiterations, whereas written communication is almost always well-planned and organized, so it can be said that while the written form of expressing apologies a very convenient one, the spoken form is more spontaneous and "warm". For this reason we decided to divide the corpus into spoken and written, formal and informal types to enlighten the syntactic, semantic and pragmatic features of expressions of apologies, believing that the obtained results would be transparent to the readers of this paper.

Inquiry into the speech act of apologies is likely to have gained popularity due to their function of maintaining and restoring good relations in a society (Grainger \& Harris, 2007). According to Grainger and Harris, studies on apologies are not only integrated into pragmatics and politeness theory, but also into other disciplines such as sociolinguistics, social psychology, philosophy, and foreign language teaching. A number of common social factors such as age, gender, personal relationships, social power and status, and discourse contexts, and situations have often been incorporated into investigation of apologies (Blum-Kulka and Olshtain, 1984).

The study carried out by Janet Holmes (1990) examined apologies based on a corpus of 183 conversations in New Zealand English. She considered some characteristics of apologies in informal remedial interchanges within the context of Brown and Levinson's $(1978,1987)$ model of politeness in language. The discussion covered a wide range of elements, including the functions of apologies, the range of strategies used to apologize, their semantic and syntactic structure, and sociolinguistic aspects of apologies. Specifically, Holmes explored apologies in various aspects such as the relationship between the complexity of apology and the weightiness of the offence which elicited it, as well as the relationship between this speech act and the gender of the speaker. Then, apologies were assessed in terms of Brown and Levinson's (1987) model, referring to rank of the imposition, power of the hearer over the speaker, distance between the participants. These social factors had previously been regarded as influential in the realization of apologies (Brown \& Levinson, 1987). Holmes $(1990,1995)$ claims that apologies seem to provide a rich source of information on the ways language interacts with society. Apart from these factors, however, other prominent facets such as situation, degree of offence, and frequency of apology are also believed to be influential (Brown \& Levinson, 1987). 


\section{Theoretical Background}

Bergman and Kasper (1993) defined an apology as a "compensatory action to an offense in the doing of which S was casually involved and which is costly to $\mathrm{H}^{\prime \prime}(\mathrm{p} .82)$. The cost can be in terms of losing face or even a severe misunderstanding. It is clear that different cultures have different degrees in perceiving how costly such an offense is, and therefore how necessary an apology is. An action, in the opinion of the authors, that is considered very serious in one culture, may not require an apology at all in another culture. Also, the severity of such a face threatening act seems to be in a direct relationship with the type of apology chosen to defend face.

Penelope Brown and Steven Levinson (1987) claimed that all speakers choose the same strategy under the same conditions, and tried to demonstrate this by looking at three different languages, namely English, Tzeltal (a Mayan language), and South Indian Tamil. However, this theory has been challenged by several researchers who claim that different individual factors are involved in both considering an act as face threatening, and the strategy used in apologizing (Trosborg, 1987). In the opinion of Trosborg these factors are determined by one's social and cultural patterns, and by the behavioral norms of one's culture. This leads to the assumption that not only do speakers of different languages perceive the necessity of an apology differently, but also use different ways of apologizing.

Differences in apology strategy use are thought to be correlated with cross-cultural differences by both inter language studies and studies that looked at the way speakers of different languages apologize in their own language. Such studies seem to give a clearer view on the relationship between speech acts and cultural factors (Barnlund \& Yoshioka, 1990; Suszczynska, 1999). The choice of apology strategies is also determined by social differences such as sex, age, and social status. Holmes (1993) has shown in a study on New Zealanders that there are significant differences in the distribution of apologies between men and women, and also that women apologize more than men.

A definition that limits very much the concept of an apology is the one given by Owen (1983). According to the author, apologies are remedial moves that follow what he called a priming move on the part of the person who expects the apology, which is a move that triggers the apology. While such an approach makes sense, the problem with Owen's definition is that he restricts the use of the term apology to only those utterances that actually contain the explicit phrases "I'm sorry" or "I apologize" and variants of these.

Geoffrey Leech (1983) viewed apologies as an attempt to recreate an imbalance between the speaker and the hearer created by the fact that the speaker committed an offence against the hearer. According to him, it is not enough to apologize, this apology needs to be successful in order for the hearer to pardon the speaker, and thus reestablish the conversational balance.

Finally, Janet Holmes (1990) defined apologies as "social acts conveying affective meaning" (Holmes, 155), believing they are politeness strategies meant to remedy an offense on the part of the speaker. Holmes also made an interesting and important clarification in defining apologies that has not been considered before. Thus, when defining apologies, one must take into consideration the possibility of a speaker to apologize for somebody else's behavior. This leads to the conclusion that "the definition refers to the person who takes responsibility for the offense rather than the offender" (Holmes, 161).

\section{Classification of Apologies}

The way apologies are classified depends very much on the way they are defined. Thus, the diversity in definitions of apologies also brings about diversity in classification.

Bergman and Kasper (1993) distinguished seven different apology categories ${ }^{1}$. Janet Holmes (1990) divided apologies into four main categories, each category having sub classifications², Anna Trosborg (1995) distinguished five

\footnotetext{
1 In the opinion of the authors, the most commonly used seems to be the Illocutionary Force Indicating Device (IFID) such as in "I'm sorry." The other strategies are intensified IFID ("I'm terribly sorry"), taking responsibility ("I haven't graded it yet"), giving an account of the reasons that led to the action that requires an apology ("I was suddenly called to a meeting"), minimizing the effects and severity of the action ("I'm only 10 minutes late"), offering repair or compensation ("I'll pay for the damage"), and verbal redress ("It won't happen again").

2 The first one is "an explicit expression of apology" and contains the subcategories "offer apology/IFID," "express regret," "request forgiveness." The second main category is represented by "an explanation or account, an excuse or justification." The largest group, "an acknowledgment of responsibility," contains "accept blame," "express self-deficiency," "recognize H as entitled to an apology," "express lack of intent," "offer repair/redress." Finally, the last category is "a promise of forbearance" (p. 167). While most of these categories are present in other taxonomies, as well, one can note that most of the ones in the "acknowledgment of responsibility" group are unique.
} 
categories $^{3}$ and Marion Owen (1983) classified apologies by the type of utterance they incorporate ${ }^{4}$, while Bruce Fraser (1981) designed a categorization of apologies based on the intent of the speaker distinguishing eight categories 5 .

A completely different approach to creating taxonomy of apologies has been attempted by Deutschmann (2003) who, after analyzing The British National Corpus, proposed three main categories of apologies according to the function they express ${ }^{6}$ while we have classified this speech act according to the formal/ informal and written/ spoken discourse. The following table shows the distribution of the polite forms of expressing apologies in the English language:

Table 1: Classification of the apologies according to type of discourse and style

\begin{tabular}{|c|c|c|}
\hline Type of Discourse & Formal English & Informal English \\
\hline Written & $\begin{array}{l}\text { The forms oriented towards the speaker } \\
\text { 1. We are very/truly/deeply/sincerely sorry for.... } \\
\text { 2. Modal verb would followed by the verbs offer i } \\
\text { like: We would like to offer sincerest apology for.... } \\
\text { The forms oriented towards the hearer } \\
\text { 1. Those preceded by please: Please accept } \\
\text { our/my (sincere/ sincerest) apology.... } \\
\text { 2. Conditional constructions: If you could accept ur } \\
\text { apology....oriented towards the hearer. } \\
\text { 3.Modal verb would followed by the verbs offer i } \\
\text { like: We would like to ask you to accept our } \\
\text { apologies for... }\end{array}$ & $\begin{array}{l}\text { The forms oriented towards the speaker } \\
\text { 1. We are very/truly/sincerely sorry for.... } \\
\text { 2. Modal verb would followed by the verbs offer i like } \\
\text { very often follwoed by How sorry I am..... } \\
\text { The forms oriented towards the hearer } \\
\text { 1. Those preceded by please: Please accept our/my } \\
\text { (sincere/ sincerest) apology.... }\end{array}$ \\
\hline Spoken & $\begin{array}{l}\text { The forms oriented towards the speaker } \\
\text { 1. I/We am /are very/truly/sincerely sorry for.... } \\
\text { 2. The formulae containing the expression ....how } \\
\text { sorry I am/we are... } \\
\text { 3. The expresions consisting od the simple past of } \\
\text { the verb want : we wanted to say... } \\
\text { 4. Modal verb would followed by the verbs offer i } \\
\text { like: I/ we would like to apologise for.... } \\
\text { The forms oriented towards the hearer } \\
\text { 1. Those preceded by please: Please accept } \\
\text { our/my (sincere/ sincerest) apology.... }\end{array}$ & $\begin{array}{l}\text { The forms oriented towards the speaker } \\
\text { 1.The formulae I/we am/are terribly/truly/ awfully sory..... } \\
\text { 2. Forms I am sorry/ excuse me in order to interrupt the } \\
\text { hearer . } \\
\text { 3. Using the single expression sorry (for sth)... } \\
\text { 4. The verb hope used in the form of present or past } \\
\text { progressive tense : hope you could fogive me, I was } \\
\text { hoping we could overcome this situation, I hope you } \\
\text { don't/ didn't mind.... } \\
\text { The forms oriented towards the hearer } \\
\text { 1. Modal verb could followed by the conditional } \\
\text { costructions if you could forgive me, if you could forget } \\
\text { what happenned etc... } \\
\text { 2. Modal verbs will/can in a formula containig question: } \\
\text { Will/Can you forgive me for...? } \\
\text { 3. Imperative form formulated with the modal must:You } \\
\text { must forgive me... }\end{array}$ \\
\hline
\end{tabular}

\section{Language and Gender}

The research concerning the relationship between language and gender, carried out by Otto Jespersen (1922: 245) and described in his study entitled Language: Its Nature, Development and Origin is considered to be an inspiring for many other linguists interested in the same question. Peter Trudgill (1974: 92) carried out a research related to the variable $n g$ appearing in the words like hopping, skipping pronounced by the all the social classes in Norwich and concluded that there were considerable differences in pronouncing between the various social classes as well as the men and women, concluding that the women and the people belonging to the higher classes tend to use more tentative forms due to the

\footnotetext{
${ }^{3}$ Trosborg (1995) found that apologetic strategies can be divided according to whether the speaker considers that an action that requires an apology occurred or not.

4 Owen (1983) identified three types of apologies: one that incorporates "apology," "apologies," or "apologize;" one that incorporates "sorry;" and, finally, the one that is created by the phrase "I'm afraid" followed by a sentence. Owen incorporated apologies in the broader context of primary remedial moves.

${ }^{5}$ Fraser (1981, 263): 1 announcing that you are apologizing, 2 stating one's obligation to apologize, 3offering to apologize,4 requesting the hearer accept an apology,5 expressing regret for the offense, 6 acknowledging responsibility for the offending act,7promising forbearance from a similar offending act, 8 offering redress.
}

${ }^{6}$ Deutschmann's $(2003,75)$ classification looks as follows: real apologies, formulaic and "face attack" ones. 
constant pressure of the society. Ronald Macaulay carried out a similar research in 1978 whose results showed that every social class tend to use more tentative language forms in the process of conversation.

However, the research carried out on the adolescents from the working class in New Zealand (1987), as well as those performed by Janet Holms (1995) and Jennifer Coates (2004) are thought to be the most representative ones related to this issue. As we haven't found a research in which the author enlightened the relation between language and gender, or more specifically, speech act of apologizing by analyzing the conversations between one or more couples we decided to carry out one based on the material obtained in one the most popular reality shows of all times.

\section{The Case Study - Methodology and Hypothesis}

The TV show Jon \& Kate plus 8 is a reality about the couple Jon and Kate Gosselin and their eight children, showing the everyday situations they face. We chose this show since the married couple at the end of the day would analyze the situations they had been put through and we realized that the discussions, or, more precisely, the language forms, could significantly show the differences between the language of men and women. This means that we tried to get the information if Kate Gosselin is keen on using more tentative language forms in the process of conversation. Our hypothesis, concerning the speech act of apologizing, looked as follows:

1) We expected that the results of the research would show that Kate Gosselin uses, to a rather high degree, more formal and tentative forms while expressing apology towards her husband. This means higher percentage of the usage of the tentative modal verbs such as would or could, the expressions / am so/ terribly/ awfully sorry, I hope..., I didn't mean/ want to etc...

2) On the other hand, we expected that the results of the research would prove that the male correspondent, Jon Gosselin uses mainly direct forms of apologizing, even the imperative ones, as well as less tentative modal verbs such as must, will or can.

The corpus of the research consisted of the fifty episodes of the reality show, or, more precisely, 1825. The research was and empirical based on the formerly specified basis and the results were analyzed by means of statistical analysis.

\section{Discussion of the Results}

The statistic analysis showed that the respondents apologized to each other for some reason three hundred fifty-two times (352), of which John apologized one hundred eighty four times (184), and his wife a hundred and sixty-eight times (168). This data was our very interesting because we did not expect this kind of distribution of formssince the prevous researches showed that this speech act is mainly typical for female speakers.

Of the total number of statements of apology addressed to his wife by Jon Gosselin one hundred and twenty three (123) belong to those forms by which the speaking person requires the participant to overcome the situation that occurred, while the remaining sixty-one (61) to the forms where the speaking person offered an explanation an action that has led to a situation that broke the communicative equilibrium between the spouses:

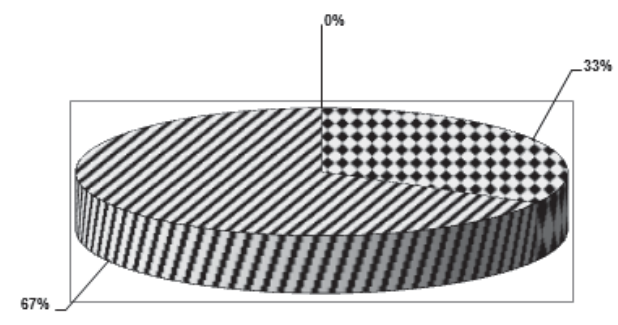

वjustify ing Drequesting $\square$

Figure 1: Distribution of speech act of apology used by Jon Gosselin in comparison to the parameter gender

On the other hand, the data collected by the study has showed that Kate Gosselin more often used those forms of 
apologising (106 form 168 or $63.09 \%$ ) by which she tried to justify and explain the actions which caused the misunderstanding:

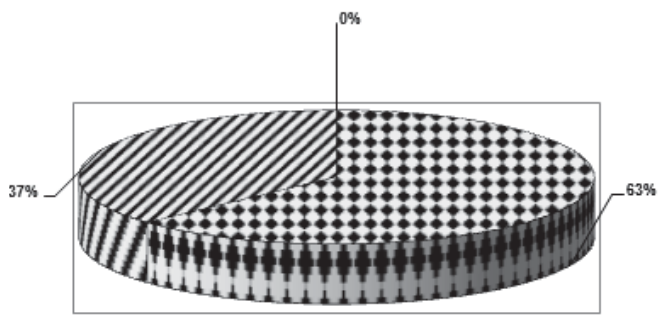

Ejustifying Drequesting $\square$

Figure 2: General distribution of speech act of apology used by Kate Gosselin in comparison to the parameter gender

Table 2: Distribution of the forms of apologies used by the respondents

\begin{tabular}{|l|c|c|c|c|}
\hline \multicolumn{1}{|c|}{ Form } & Jon & $\%$ & Kate & $\%$ \\
\hline I am so/terribly/awfully/ very sorry & 55 & 29,89 & 81 & 48,21 \\
\hline Please & 10 & 5,43 & 37 & 22,02 \\
\hline Can & 43 & 23,36 & 4 & 2,38 \\
\hline Could & 13 & 7,06 & 21 & 12,5 \\
\hline Must & 22 & 11,95 & 2 & 1,19 \\
\hline Will & 6 & 3,26 & 14 & 8,33 \\
\hline I hope & 3 & 1,63 & 1 & 0,59 \\
\hline I didn't mean/ want to... & 18 & 9,78 & 6 & 3,57 \\
\hline But & 14 & 7,6 & 2 & 1,19 \\
\hline \multicolumn{1}{|c|}{ Total } & 184 & 100 & 168 & 100 \\
\hline
\end{tabular}

The results of the case study showed that Kate Gosselin used to a higher degree more tentative forms such as the modal verb could, lexeme please as well as the structure I am so/terribly/awfully/ very sorry and the modal will, which was mainly used in the interrogative forms used for asking the correspondent whether he was willing to overcome the misunderstanding. On the other hand, the results show that Jon used the modal verbs can and must as well as the but forms (which eas used only twice by his wife) as well as the structure I didn't mean/ want to.... The reason for this can be found in a perpetual women's fear of rejection if she commits the FTA as well as the wish to be approved and accepted by the society the (Lakoff, 2004, 40). Although the obtained results proved the hypothesis, they can only be generalized when perceived with already obtained results provided by other authors (Coates, 2004; Holmes, 1995).

\section{Instead of Conclusion- Looking to the Future}

Since the beginning of the 21th century, the lingustic studies have moved from the studies of the purely language forms to the sociolinguistics. Numerous researches have been analyzing spoken an written language in order to understand how social factors, such as belonging to a certain social class, education and gender affect everyday communication. There is also an increasing need to show the similarities and differences between male and female speakers which result in "improving understanding of the variety of ways gender is manifested linguisticaly in different communities" (Coates, 221). For this reason we agree with the authors (Cameron \& Kulick, 2003; Coates, 2004; Jones, 2012) who believe that this branch of linguistic studies will continue developing with a special emphasis on bisexual, gay and lesbian speakers. 


\section{References}

Austen, J.L. (1962). How to Do Things With Words.Oxford: Claredon Press.

Barnlund D.C. \& Yoshioka M. (1990). "Apologies: Japanese and American Style". International Journal of International Relations, 14.pp. 193-206.

Bergman M. and Kasper G. (1993) perception and performance in native and non-native apology. Interlanguage Pragmatics. pp. 82-107. Oxford: Oxford University Press.

Blum-Kulka, S. and Olshtain, E. (1984). Requests and apologies: a cross- cultural study of speech act realization patterns. (CCSARP). Applied Linguistics, 5. pp. 196-2013.

Brown, P. \& Levinson, S.C. (2002). Politeness - Some Universals in Language Usage. Cambridge: CUP.

Cameron, D. \& Kulik, D. (2003). Language and Sexuality. Cambridge: United Kingdom at the University Press.

Coates, J. (2004). Women, Men and Language. Pearson Longman.

Deutschmann, M. (2003). Apologizing in British English. Umeå: Umeå Universitet.

Fraser, B. (1981). "On Apologizing" in Conversational Routine: Explorations in Standardized Communication Situations and Prepatterned Speech. Ed. Florian Coulmas. The Hague: Mouton. Pp. 259-271.

Grainger, K. \& Harris, S. (2007). "Introduction: A Special Issue on Apologies". Journal of Politeness Research. 3 (1). pp. 1-10.

Holmes, J. (1995). Women, Men and Politeness. London: Longman.

Jespersen, O. (1922). Language: Its Nature, Development and Origin. London: Alen and Unwin.

Jones, L. (2012). Language and Identity in a Lesbian Group.New York: Palgrave Macmillan.

Lakoff, R.T. (1975). Language and Woman's Place. New York: OUP.

Leech, G. N. (1983). Principles on Pragmatics. London: Longman.

Owen, M. (1983). Apologies and Remedial Interchanges: A Study of Language Use in Social Interaction . Berlin: Mouton De Gruyter.

Searle, J.R. (1969). Speech acts: An essay in the philosophy of language. London: CUP.

Sifianou, M. (2000). Politeness Phenomena in England and Greece: A Cross Cultural Perspective, OUP.

Suszczynska, M. (1999). "Apologizing in English, Polish and Hungarian: Different Languages, Different Strategies". Journal of Pragmatics, 31(8). pp. 1053-1065.

Trosborg, A. (1987). "Apology Strategies in Native/ Non-Natives". Journal of Pragmatics. pp. 147-167.

Watts, R. J. (2003). Politeness. Cambridge: CUP.

Holmes (1993) Coates 